\title{
Valor nutricional do capim-elefante verde colhido em diferentes
} idades de rebrota

[Nutritional value of fresh elephantgrass harvested at different regrowth ages]

\author{
L.F. Martins ${ }^{1}$, D.M.B. Prado ${ }^{2}$, G.R. Gomes ${ }^{2}$, A.M. Teixeira ${ }^{3}$,
} L.N. Oliveira ${ }^{4}$, L.C. Gonçalves ${ }^{5}$, F.S. Oliveira ${ }^{6}$

\author{
${ }^{1}$ Aluno de pós-graduação - Universidade Purdue - Colégio de Medicina Veterinária - West Lafayette, IN, EUA \\ ${ }^{2}$ Aluno de pós-graduação - Universidade Federal de Uberlândia, FAMEV - Uberlândia, MG \\ ${ }^{3}$ Universidade Federal de Minas Gerais, Escola de Veterinária - Belo Horizonte, MG \\ ${ }^{4}$ Aluno de pós-graduação - Universidade Federal de Lavras - Lavras, MG \\ ${ }^{5}$ Universidade Federal de Uberlândia, FAMEV - Uberlândia, MG \\ ${ }^{6}$ Aluno de graduação - Universidade Federal de Uberlândia, FAMEV - Uberlândia, MG
}

\section{RESUMO}

Avaliou-se o valor nutricional do capim-elefante verde colhido aos 56, 84 e 112 dias de idade, por meio do consumo e da digestibilidade em ovinos, da degradabilidade in situ e da cinética da fermentação ruminal. O capim-elefante colhido aos 56 dias proporcionou maiores valores de consumo da MS (1204,81g/dia), da EB $(4910,41 \mathrm{kcal} / \mathrm{dia})$, da ED $(3436,21 \mathrm{kcal} / \mathrm{dia})$ e da PB (130,90g/dia). Para o capim-elefante colhido aos 56 dias, ainda foram observados os maiores valores de digestibilidade da MS (70,64\%), da EB (70,11\%), da PB $(68,96 \%)$, da FDN $(71,4 \%)$ e do conteúdo ED (2,86Mcal/kg MS). Com o avanço da idade de corte, houve redução da degradabilidade potencial da MS (77,99\% x 68,33\%), da PB $(84,80 \% \times 56,52 \%)$ e da FDN $(72,18 \% \times 64,33 \%)$, para as idades de corte de 56 e 112 dias, respectivamente. O capim cortado aos 56 dias apresentou maior valor de produção cumulativa de gases $(210,50 \mathrm{~mL} / \mathrm{g}$ de MS) e de degradabilidade da matéria seca $(63,9 \%)$ após 96 horas de fermentação. O capim-elefante verde deve ser colhido aos 56 dias de rebrota em razão das características nutricionais apresentadas.

Palavras-chave: cinética de fermentação, consumo, degradabilidade in situ, digestibilidade, Pennisetum purpureum

\begin{abstract}
The nutritional value of fresh elephant grass harvested at 56, 84 and 112 days of age was evaluated by intake and digestibility in sheep, in situ degradability, and ruminal fermentation's kinetics. The elephant grass harvested at 56 days provided higher DM intake (1204.81g/day), GE (4910.41kcal/day), DE (3436.21 kcal/day), and CP (130.90g/day) values. Furthermore, the highest DM (70.64\%), GE (70.11\%), $D E(2.86 \%)$ and $C P(68.96 \%)$ digestibility values were observed at 56 days. With the increase in the harvest age there was a reduction in the DM (77.99 $\times 68.33 \%), C P(84.80 \times 56.52 \%)$ and NDF $(72.18 \times 64.33 \%)$ potential degradability in the treatments 56 and 112 days, respectively. Higher values of cumulative gas production $(210,50 \mathrm{~mL} / \mathrm{g} D M)$ and DM degradability for elephant grass were observed at 56 days, after 96 hours of fermentation. The fresh elephant grass should be harvested at 56 days of regrowth due to the nutritional characteristics found in this study.
\end{abstract}

Keywords: fermentation's kinetics, intake, in situ degradability, digestibility, Pennisetum purpureum

\section{INTRODUÇÃO}

Devido ao elevado potencial produtivo, ao bom valor nutricional e à possibilidade de uso na forma de corte, pastejo e silagem, o capim-elefante apresenta-se como boa opção de volumoso para a nutrição de ruminantes no Brasil. O valor nutricional de gramíneas forrageiras está 
associado ao momento de colheita ou corte dos materiais, uma vez que o avanço do estádio de maturação pode influenciar negativamente $o$ consumo e a digestibilidade do alimento. Dessa maneira, faz-se necessário determinar estratégias de utilização das gramíneas forrageiras por meio de técnicas de avaliação do valor nutricional.

Machado et al. (2008) encontraram valores de proteína bruta $(\mathrm{PB})$, fibra insolúvel em detergente neutro (FDN) e nutrientes digestíveis totais (NDT) variando entre $5,18 \%$ e $14,10 \%$; entre $60,62 \%$ e $69,58 \%$ e entre $55,22 \%$ e $68,89 \%$, respectivamente, para o cv. Cameroon com idade de rebrota entre 33 e 93 dias, assim como Lima et al. (2008) relataram teores de PB de $10,16 \%$ e $12,54 \%$ em diferentes genótipos colhidos aos 56 dias de crescimento. Desse modo, objetivou-se determinar o melhor momento para utilização do capim-elefante verde como forrageira de corte, por meio de ensaios de consumo, digestibilidade, degradabilidade in situ e cinética de fermentação ruminal.

\section{MATERIAL E MÉTODOS}

A colheita do material foi realizada na Fazenda Experimental Professor Hélio Barbosa da Escola de Veterinária da Universidade Federal de Minas Gerais (UFMG). Foi utilizada uma área já estabelecida de capim-elefante (Pennisetum purpureum Schum.), cuja fertilidade do solo foi corrigida no início da época das águas, por meio da aplicação de $300 \mathrm{~kg} /$ hectare do fertilizante comercial 20:05:20, com base nas análises químicas e físicas do solo. Decorridos 30 dias da aplicação, no dia 06 de janeiro de 2007, foi realizado um corte para uniformização da altura do dossel a $20 \mathrm{~cm}$ do nível do solo, sendo o capim posteriormente cortado com roçadeira costal, nas idades experimentais de 56, 84 e 112 dias, sempre na mesma altura de resíduo.

O material picado foi imediatamente processado em picadeira estacionária de partículas, com regulagem de corte para $10 \mathrm{~mm}$ a $30 \mathrm{~mm}$, ensacado, e levado à Escola de Veterinária para ser armazenado em câmara fria a $-17^{\circ} \mathrm{C}$. Posteriormente, durante o ensaio com animais, os sacos contendo capim picado eram retirados diariamente da câmara fria, para que o material descongelasse por um período de 24 horas, em temperatura ambiente. Todos os procedimentos experimentais com animais foram aprovados pelo
Comitê de Ética em Experimentação Animal (Cetea/UFMG), sob certificado de número 43/2009.

$\mathrm{O}$ ensaio de consumo e digestibilidade foi conduzido no Laboratório de Metabolismo e Calorimetria Animal - Lamca, do Departamento de Zootecnia da EV-UFMG. Foram utilizados 18 carneiros adultos, sem raça definida (SRD), com peso médio de $34,7 \mathrm{~kg}$, e distribuídos, de forma aleatória, em gaiolas metabólicas individuais com piso ripado, dotadas de bebedouro e comedouro em aço inoxidável e saleiro de PVC. As gaiolas possuíam funis acoplados ao piso de madeira, abaixo dos quais eram colocadas caixas plásticas, para coleta de fezes, e baldes plásticos com telas, para coleta de urina. Aos baldes de urina, foram adicionados, diariamente, $100 \mathrm{~mL}$ de ácido clorídrico $(\mathrm{HCl} 2 \mathrm{~N})$. O período experimental foi de três dias após 21 dias de adaptação às dietas e às gaiolas.

$\mathrm{O}$ alimento foi oferecido de modo a se obter entre $10 \%$ e $20 \%$ de sobras no cocho; a água e uma mistura mineral comercial foram fornecidos $a d$ libitum, sendo os bebedouros higienizados diariamente. Foram realizadas amostragens diárias do oferecido, sobra, fezes e urina, durante o período de coleta. As sobras e as fezes foram pesadas diariamente em dois períodos (às sete horas e às 17 horas), sendo armazenados $20 \%$ do total por animal por dia. A urina foi coletada uma vez ao dia (às sete horas), sendo determinado o volume para armazenamento de $10 \%$ do total.

As amostras coletadas foram pré-secas em estufa a $55^{\circ} \mathrm{C}$, por 72 horas, e processadas a $1 \mathrm{~mm}$ em moinho estacionário do tipo Willey, sendo posteriormente encaminhadas, em duplicatas, para determinação da matéria seca (MS) em estufa a $105^{\circ} \mathrm{C}$ (Official..., 1980); proteína bruta (PB) e conteúdo de nitrogênio $(\mathrm{N})$ pelo método de Kjeldahl (International..., 1995); fibra insolúvel em detergente neutro (FDN), fibra insolúvel em detergente ácido (FDA), hemiceluloses, celulose e lignina pelo método sequencial de Van Soest $e t$ al. (1991); energia bruta (EB) por combustão em bomba calorimétrica adiabática modelo PARR 2081 (International..., 1995). Na urina foram determinados os teores de EB, nitrogênio e PB, seguindo as metodologias mencionadas. Apenas nas amostras do oferecido foram determinados, também, os teores de extrato etéreo (EE) (International..., 1995); nitrogênio insolúvel em 
detergente neutro (NIDN) e nitrogênio insolúvel em detergente ácido (NIDA) (Van Soest et al., 1991).

O consumo voluntário de nutrientes do capimelefante foi calculado pela diferença entre $o$ alimento oferecido aos animais e as sobras nos cochos, sendo os valores de digestibilidade aparente obtidos por meio da coleta total de fezes, conforme Silva e Leão (1978). Os valores de energia digestível (ED) foram determinados pela diferença entre os valores de energia bruta ingerida e a perdida nas fezes. Para o ensaio de degradabilidade in situ, foram utilizadas cinco vacas da raça Holandês, com peso corporal médio de $550 \mathrm{~kg}$, fistuladas no rúmen. Os animais permaneceram em um piquete que dispunha de bebedouro e comedouro, onde recebiam silagem de milho à vontade e $2 \mathrm{~kg}$ de um concentrado comercial (20\% de PB) por dia.

Foram utilizados sacos de náilon com poros de $50 \mu \mathrm{m}$, previamente lavados em água corrente e secos a $55^{\circ} \mathrm{C}$, por 24 horas. Em cada saco, foram adicionados $5 \mathrm{~g}$ do capim pré-seco, moído a $5 \mathrm{~mm}$, correspondendo a uma relação de $17 \mathrm{mg}$ de amostra por $\mathrm{cm}^{2}$. Os tempos de incubação adotados para a avaliação da degradabilidade in situ foram seis, 12, 24, 48 e 96 horas. Foram incubados dois sacos por tratamento para os tempos de seis e 12 horas, três sacos para os tempos de 24 e 48 horas e quatro sacos para o tempo de 96 horas. A determinação do tempo zero $\left(\mathrm{t}_{0}\right)$ foi feita lavando-se os sacos em água corrente.

Os resíduos de incubação, referentes a um mesmo animal em tempos de degradação e tratamentos iguais, foram homogeneizados, pré-secos em estufa a $55^{\circ} \mathrm{C}$, por 72 horas, e processados a $1 \mathrm{~mm}$ em moinho estacionário do tipo Willey, para posterior realização de análises de MS, PB e conteúdo de nitrogênio, FDN, FDA, hemiceluloses, celulose e lignina, conforme metodologias descritas anteriormente.

A avaliação do capim-elefante verde pela técnica in vitro semiautomática de produção de gases foi realizada conforme metodologia proposta por Maurício et al. (1999). O líquido ruminal foi retirado via fístula ruminal, pela manhã, antes da alimentação dos animais, e armazenado em garrafas térmicas previamente aquecidas. No laboratório de produção de gases, frascos de fermentação de $160 \mathrm{~mL}$ foram gaseados com $\mathrm{CO}_{2}$ para manter o máximo de anaerobiose. Foram adicionados $1 \mathrm{~g}$ de substrato (capim pré-seco e moído a $1 \mathrm{~mm}$ ) e $90 \mathrm{~mL}$ do meio de cultura preparado de acordo com a metodologia de Theodorou et al. (1994).

Os líquidos ruminais foram filtrados por meio de uma bolsa de dácron, com porosidade de 44 micras, sob injeção continua de $\mathrm{CO}_{2}$, e mantidos em banho-maria a $39^{\circ} \mathrm{C}$. Os inóculos de cada animal foram utilizados como fonte de repetição, sendo cada tratamento submetido a cada tipo de inóculo separadamente. A inoculação foi realizada por meio da injeção de $10 \mathrm{~mL}$ de cada inóculo por frasco, com seringa plástica graduada. Os frascos foram tampados e, após a inoculação de cada caixa de incubação com capacidade para 28 frascos, foi introduzida e retirada imediatamente uma agulha nas tampas. As caixas contendo os frascos foram agitadas manualmente e, em seguida, incubadas em estufa a $39^{\circ} \mathrm{C}$. As leituras de pressão foram realizadas em intervalos de duas, quatro, seis, oito, 10, 12, 15, 19, 24, 30, 34, 48, 72 e 96 horas após incubação e transformadas em volume de gases pela equação definida por Maurício et al. (2003).

As degradabilidades in vitro da MS foram determinadas pela filtragem do conteúdo dos frascos em cadinhos de borosilicato com porosidade 1 , os quais foram acrescidos de lã de vidro nos tempos de seis, 12, 24, 48 e 96 horas. Os cadinhos foram, então, mantidos por 24 horas, em estufa a $105^{\circ} \mathrm{C}$, sendo posteriormente pesados, e o peso utilizado para o cálculo da degradabilidade da MS. Os cadinhos com os resíduos de matéria seca foram levados para uma mufla a $500^{\circ} \mathrm{C}$, durante três horas, para determinação da matéria mineral, que foi posteriormente utilizada para determinar a degradação da matéria orgânica.

Para o ensaio de consumo e digestibilidade aparente, o delineamento experimental adotado foi o inteiramente ao acaso, com três tratamentos e seis repetições. Os dados obtidos foram submetidos à análise de variância, utilizando-se o pacote estatístico PROC do software SAS (SAS, 1993), e as médias comparadas pelo teste SNK ao nível de $5 \%$ de probabilidade $(\mathrm{P}<0,05)$.

Os parâmetros de degradabilidade in situ foram obtidos pelo algoritmo de MARQUARDT, do programa estatístico computacional SAEG (Euclydes, 1983). Os dados das degradações dos 
constituintes da forrageira foram submetidos a uma análise de regressão, na qual foram regredidos ao modelo de Orskov e Mcdonald (1979). O tempo de colonização foi estimado conforme McDonald (1981). Para as frações dos constituintes da parede celular (FDN e FDA, a fração solúvel "S" foi considerada zero segundo Valadares Filho (1994). A degradabilidade efetiva (DE) de cada componente nutricional foi calculada com base no modelo proposto por Orskov e Mcdonald (1979).

Para a análise dos dados de desaparecimento dos componentes nutricionais das forrageiras, foi empregado um delineamento experimental de blocos ao acaso, em esquema de parcelas subdivididas, tendo os animais como blocos, as forrageiras como parcelas e os tempos de incubação como subparcelas. As médias foram comparadas empregando-se o teste SNK, ao nível de $5 \%$ de probabilidade $(\mathrm{P}<0,05)$. Os dados da cinética de produção de gases e da degradabilidade foram submetidos à análise de regressão pelo programa estatístico SAEG (Euclydes, 1983) e regredidos ao modelo de France et al. (1993).

Foram calculados os valores das degradabilidades efetivas da matéria seca para as taxas de passagem de 2 e $5 \%$ /hora para baixo e médio consumos, respectivamente, conforme recomendações do
Agricultural Research Council (The nutriente..., 1984), empregando-se a equação proposta por France et al. (1993). Os valores das produções acumulativas de gases e degradabilidade da matéria seca foram analisados utilizando-se delineamento experimental de blocos ao acaso, em esquema de parcelas subdivididas, tendo como fonte de variação os inóculos (blocos), os fenos produzidos nas idades de corte (parcelas) e os tempos de incubação (subparcelas). O teste estatístico utilizado na comparação das médias dos tratamentos foi o teste SNK $(\mathrm{P}<0,05)$, com o auxílio do software SAEG (Euclydes, 1983).

\section{RESULTADOS E DISCUSSÃO}

A composição química e os valores de energia do capim-elefante verde colhido em diferentes idades podem ser observados na Tab. 1. Os teores de MS, MO, NIDN, NIDA, FDN, FDA e lignina apresentaram aumento com o avanço da idade de corte, e os teores de PB, EE, cinzas e DIVMS apresentaram comportamento inverso. Foram observados valores de MS superiores aos relatados na literatura por Silva et al. (2007) e Lima et al. (2008). O processamento prévio em picadeira associado ao descongelamento pode ter proporcionado maior perda de água intrínseca da planta, justificando esse resultado.

Tabela 1. Composição química e valores de energia bruta do capim-elefante (Pennisetum purpureum Schum.) verde cortado aos 56, 84 e 112 dias de crescimento

\begin{tabular}{llll}
\hline \multirow{2}{*}{ Nutrientes } & \multicolumn{3}{l}{ Idade de corte (dias) } \\
\cline { 2 - 4 } & 56 & 84 & 112 \\
\hline Matéria seca $^{1}$ & 17,08 & 22,44 & 25,20 \\
Matéria orgânica $^{2}$ & 88,80 & 91,56 & 92,90 \\
Proteína bruta $^{2}$ & 10,91 & 6,89 & 5,05 \\
Nitrogênio insolúvel em detergente neutro $^{3}$ & 32,05 & 40,60 & 46,72 \\
Nitrogênio insolúvel em detergente ácido $^{3}$ & 16,70 & 26,33 & 34,77 \\
Extrato etéreo $^{2}$ & 2,27 & 1,68 & 1,45 \\
Fibra insolúvel em detergente neutro $^{2}$ & 66,76 & 71,62 & 74,05 \\
Fibra insolúvel em detergente ácido $^{2}$ & 37,19 & 44,77 & 44,53 \\
Lignina $^{2}$ & 3,59 & 5,60 & 6,51 \\
Hemiceluloses $^{2}$ & 29,57 & 26,85 & 29,52 \\
Celulose $^{2}$ & 33,60 & 39,17 & 38,02 \\
Cinzas $^{2}$ & 11,20 & 8,44 & 7,10 \\
Digestibilidade $^{\text {in }}$ vitro da matéria seca & \\
Energia bruta $^{2}$ & 69,44 & 58,62 & 53,99 \\
\hline
\end{tabular}

${ }^{1}$ Porcentagem da matéria original; ${ }^{2}$ porcentagem da matéria seca; ${ }^{3}$ porcentagem do nitrogênio total; ${ }^{4} \mathrm{Mcal} / \mathrm{kg}$ de matéria seca. 
Os consumos (g/dia) de MS, EB, ED, PB e hemiceluloses foram superiores para o capimelefante verde cortado aos 56 dias de idade, e não diferiram entre as idades de 84 e 112 dias. Não houve diferença para os consumos (g/dia) de FDN, FDA, celulose e lignina (Tab. 2). Os consumos por unidade de tamanho metabólico (g/UTM/dia) apresentaram comportamento semelhante, exceto para lignina, cujos valores, aos 84 e 112 dias, foram superiores aos encontrados em 56 dias de idade. Os valores de consumo de MS (g/UTM/dia) estão coerentes com o intervalo descrito por McDonald et al. (1981) para consumo de forragens frescas, que é de 40 a 100g/UTM/dia. A digestibilidade aparente de todos os nutrientes avaliados bem como o consumo de nutrientes digestíveis (MS e PB) foram superiores para o capim-elefante cortado aos 56 dias de idade, e não diferiram entre as idades de 84 e 112 dias.

Tabela 2. Consumo voluntário de nutrientes (gramas ou kcal/dia), consumo voluntário de nutrientes por unidade de tamanho metabólico (gramas ou kcal/UTM/dia), digestibilidade aparente de nutrientes (digestibilidade) (\%) e consumo de nutriente digestível (CND) por unidade de tamanho metabólico (gramas/UTM/dia) de carneiros alimentados com capim-elefante (Pennisetum purpureum Schum.) verde cortado aos 56, 84 e 112 dias de crescimento

\begin{tabular}{|c|c|c|c|c|c|}
\hline \multirow[b]{2}{*}{ Nutrientes } & \multirow[b]{2}{*}{$\begin{array}{l}\text { Idade } \\
\text { corte }\end{array}$} & \multicolumn{4}{|c|}{ Item } \\
\hline & & $\begin{array}{l}\text { Consumo (g ou } \\
\text { kcal/dia) }\end{array}$ & $\begin{array}{l}\text { Consumo (g ou } \\
\text { kcal/UTM/dia) }\end{array}$ & $\begin{array}{c}\text { Digestibilidade } \\
(\%)\end{array}$ & $\begin{array}{c}\text { CND } \\
\text { (g/UTM/dia) }\end{array}$ \\
\hline \multirow{3}{*}{ MS (gramas) } & 56 & $1204,81 \mathrm{~A}$ & $81,12 \mathrm{~A}$ & $70,64 \mathrm{~A}$ & $57,26 \mathrm{~A}$ \\
\hline & 84 & $934,77 \mathrm{~B}$ & $65,39 \mathrm{~B}$ & $57,28 \mathrm{~B}$ & $37,48 \mathrm{~B}$ \\
\hline & 112 & $809,85 \mathrm{~B}$ & $60,28 \mathrm{~B}$ & $57,23 \mathrm{~B}$ & $34,95 \mathrm{~B}$ \\
\hline \multirow[t]{2}{*}{$\mathrm{CV}(\%)$} & & 21,14 & 17,44 & 7,71 & 21,64 \\
\hline & 56 & $4910,41 \mathrm{~A}$ & $330,62 \mathrm{~A}$ & $70,11 \mathrm{~A}$ & - \\
\hline \multirow[t]{2}{*}{ EB (kcal) } & 84 & $3784,46 \mathrm{~B}$ & $264,74 \mathrm{~B}$ & $56,87 \mathrm{~B}$ & - \\
\hline & 112 & 3384,30B & $252,15 \mathrm{~B}$ & $57,99 \mathrm{~B}$ & - \\
\hline \multirow[t]{2}{*}{$\mathrm{CV}(\%)$} & & 21,35 & 18,04 & 7,80 & - \\
\hline & 56 & $3436,21 \mathrm{~A}$ & $231,74 \mathrm{~A}$ & $2,86^{*} \mathrm{~A}$ & - \\
\hline \multirow[t]{2}{*}{$\mathrm{ED}$ (kcal) } & 84 & $2143,13 B$ & $150,69 \mathrm{~B}$ & $2,30 * \mathrm{~B}$ & - \\
\hline & 112 & $1969,77 \mathrm{~B}$ & $148,62 B$ & $2,42 * \mathrm{~B}$ & - \\
\hline \multirow{2}{*}{$\mathrm{CV}(\%)$} & & 23,03 & 22,45 & 9,31 & - \\
\hline & 56 & $130,90 \mathrm{~A}$ & $8,81 \mathrm{~A}$ & $68,96 \mathrm{~A}$ & $6,09 \mathrm{~A}$ \\
\hline \multirow[t]{2}{*}{ PB (gramas) } & 84 & $64,87 \mathrm{~B}$ & $4,54 \mathrm{~B}$ & $52,52 \mathrm{~B}$ & $2,40 \mathrm{~B}$ \\
\hline & 112 & $41,54 \mathrm{~B}$ & $3,09 \mathrm{C}$ & $44,84 \mathrm{~B}$ & $1,44 \mathrm{~B}$ \\
\hline \multirow[t]{2}{*}{$\mathrm{CV}(\%)$} & & 25,17 & 19,37 & 15,94 & 25,94 \\
\hline & 56 & 797,91 & 53,70 & $71,40 \mathrm{~A}$ & - \\
\hline \multirow[t]{2}{*}{ FDN (gramas) } & 84 & 660,71 & 46,21 & $57,78 \mathrm{~B}$ & - \\
\hline & 112 & 588,43 & 43,83 & $57,19 \mathrm{~B}$ & - \\
\hline \multirow[t]{2}{*}{$\mathrm{CV}(\%)$} & & 20,88 & 17,55 & 7,70 & - \\
\hline & 56 & 441,64 & 29,72 & $67,24 \mathrm{~A}$ & - \\
\hline \multirow[t]{2}{*}{ FDA (gramas) } & 84 & 416,33 & 29,12 & $58,11 \mathrm{~B}$ & - \\
\hline & 112 & 349,58 & 26,06 & $54,19 B$ & - \\
\hline $\mathrm{CV}(\%)$ & & 20,48 & 17,28 & 9,66 & - \\
\hline \multirow{3}{*}{$\begin{array}{l}\text { Hemiceluloses } \\
\text { (gramas) }\end{array}$} & 56 & $356,27 \mathrm{~A}$ & $23,98 \mathrm{~A}$ & $76,57 \mathrm{~A}$ & - \\
\hline & 84 & $244,38 B$ & $17,09 \mathrm{~B}$ & $57,15 \mathrm{~B}$ & - \\
\hline & 112 & $238,85 \mathrm{~B}$ & $17,78 \mathrm{~B}$ & $61,54 \mathrm{~B}$ & - \\
\hline \multirow[t]{2}{*}{$\mathrm{CV}(\%)$} & & 21,65 & 18,06 & 8,32 & - \\
\hline & 56 & 400,15 & 26,92 & $71,63 \mathrm{~A}$ & - \\
\hline \multirow[t]{2}{*}{ Celulose (gramas) } & 84 & 363,54 & 25,43 & $63,15 \mathrm{~B}$ & - \\
\hline & 112 & 297,65 & 22,19 & $59,15 \mathrm{~B}$ & - \\
\hline $\mathrm{CV}(\%)$ & & 20,85 & 17,42 & 8,46 & - \\
\hline
\end{tabular}

MS = matéria seca; EB = energia bruta; ED = energia digestível; $\mathrm{PB}=$ proteína bruta; FDN = fibra insolúvel em detergente neutro; FDA = fibra insolúvel em detergente ácido; $\mathrm{CV}=$ coeficiente de variação; $* \mathrm{Mcal} / \mathrm{kg}$ de matéria seca. Letras maiúsculas diferentes nas colunas representam diferença estatística $(\mathrm{P}<0,05 ; \mathrm{SNK})$. 
Devido ao aumento nos teores das frações fibrosas e à lenta digestão dessa fração no trato gastrointestinal (Van Soest, 1994), o capimelefante cortado em idades mais avançadas apresenta um maior tempo de retenção prégástrica, o que resulta em maior efeito de enchimento ruminal e, consequentemente, comprometimento do consumo de matéria seca. Assim, o maior consumo de capim-elefante cortado aos 56 dias pode estar relacionado, entre outros fatores, ao menor conteúdo de FDN desse material (Tab. 1).

A redução da digestibilidade dos nutrientes do capim-elefante em função das idades de rebrota está associada, principalmente, à diminuição do teor proteico da forrageira e ao aumento dos teores de FDN e FDA indigestíveis e de lignina (Machado et al., 2008), fatores também observados no presente estudo. Além disso, foi observada queda na digestibilidade da proteína bruta, que pode estar relacionada ao maior percentual de compostos nitrogenados indisponíveis à fermentação animal com o avanço do estádio de maturação do capim-elefante, evidenciado pelos valores de nitrogênio insolúvel em detergente ácido (NIDA) (Tab. 1).

Machado et al. (2008), ao avaliarem a digestibilidade ruminal da proteína bruta do capim-elefante cv. Cameroon em diferentes idades de corte, encontraram valores negativos para o capim cortado a partir de 48 dias de rebrota, o que poderia estar limitando o crescimento microbiano devido à deficiência de proteína degradável no rúmen. No presente estudo, observou-se correlação positiva ente a digestibilidade da FDN e o consumo de proteína digestível ( $\mathrm{r}=0,8393 ; \mathrm{P}<0,0001)$, ressaltando-se a importância de teores adequados de nitrogênio no rúmen para um melhor desenvolvimento microbiano.

Com o avanço da idade de corte, houve redução da degradabilidade potencial da MS, tendo as idades de 84 e 112 dias apresentado valores próximos (Tab. 3). A taxa constante de degradação da matéria seca (c) apresentou redução com o avanço da idade de corte, e a degradabilidade efetiva calculada para as taxas de passagem de 2,0; 3,0 e 5,0\%/h foi superior para o capim colhido mais novo (56 dias). A degradabilidade potencial da PB variou entre $56,52 \%$ e $84,80 \%$ (Tab. 3), sendo grande parte dessa diferença associada à solubilidade da fração proteica $(45,09 \% ; 25,53 \% ; 22,98 \%$ aos 56,84 e 112 dias, respectivamente).

Considerando-se taxas de passagem de 2,0; 3,0 e $5,0 \%$ /hora, os maiores valores de degradabilidade efetiva da PB foram observados para o capimelefante cortado aos 56 dias de crescimento, seguido pela idade de 84 dias e, por último, pela idade de 112 dias. Boa parte do nitrogênio (14\% a $34 \%$ ) presente nas forragens está na forma de nitrogênio não proteico (Van Soest, 1994), o qual apresenta alta solubilidade e taxa de degradação no rúmen tendendo ao infinito (Santos, 2006). Esse fato explica o elevado valor da fração solúvel obtido para o capim colhido mais novo.

A fração potencialmente degradável da FDN do capim-elefante verde foi de $72,15 \% ; 61,44 \%$ e 64,20\% para as idades de 56, 84 e 112 dias, respectivamente (Tab. 3). Devido aos baixos valores da fração solúvel, para a FDN os valores de degradabilidade potencial são praticamente equivalentes aos da fração potencialmente degradável. A taxa de degradação se reduziu em razão do avanço no estádio de maturação, variando de 2,03 a 3,89\%/hora. Paras as taxas de passagem de 2,0; 3,0 e 5,0\%/hora, o capimelefante verde apresentou percentuais de degradabilidade efetiva da FDN entre $18,70 \%$ e $47,67 \%$. Assim como para a MS, os altos valores dos coeficientes de determinação encontrados indicam a boa adequação dos resultados de desaparecimento de FDN ao modelo proposto por Orskov e Mcdonald (1979).

Tomich et al. (2003), ao trabalharem com capimelefante verde cortado aos 30 dias de rebrota, relataram degradabilidade potencial da FDN de $70,2 \%$ e taxa de degradação da FDN de $4,43 \%$ /hora. Para as taxas de passagem de 2,0; 5,0 e $8,0 \% /$ hora, esses autores encontraram valores para a degradabilidade efetiva da FDN de 49,4\%, $34,7 \%$ e $27,1 \%$, respectivamente. Esses valores são próximos aos resultados apresentados pelo capim-elefante verde cortado aos 56 dias de rebrota. 
Valor nutricional...

Tabela 3. Parâmetros de degradabilidade ruminal e degradabilidade efetiva da matéria seca, proteína bruta e fibra insolúvel em detergente neutro do capim-elefante (Pennisetum purpureum Schum.) verde cortado aos 56,84 e 112 dias de crescimento

\begin{tabular}{|c|c|c|c|c|c|c|c|c|}
\hline \multirow{3}{*}{ Idade corte (dias) } & \multicolumn{8}{|c|}{ Matéria seca } \\
\hline & \multirow{2}{*}{$\mathrm{a}(\%)$} & \multirow{2}{*}{$\mathrm{b}(\%)$} & \multirow{2}{*}{$\mathrm{c}(\%)$} & \multirow{2}{*}{$\mathrm{DP}$} & \multirow{2}{*}{$\mathrm{R}^{2}$} & \multicolumn{3}{|c|}{$\mathrm{DE}(\% / \mathrm{h})$} \\
\hline & & & & & & 2,0 & 3,0 & 5,0 \\
\hline 56 & 22,52 & 55,47 & 4,08 & 77,99 & 0,97 & 59,74 & 54,48 & 47,44 \\
\hline 84 & 20,76 & 48,53 & 3,29 & 69,29 & 0,96 & 50,94 & 46,14 & 40,02 \\
\hline 112 & 17,40 & 50,93 & 2,25 & 68,33 & 0,96 & 44,36 & 39,23 & 33,21 \\
\hline \multirow{3}{*}{ Idade corte (dias) } & \multicolumn{8}{|c|}{$\mathrm{PB}$} \\
\hline & \multirow{2}{*}{$\mathrm{a}(\%)$} & \multirow{2}{*}{$\mathrm{b}(\%)$} & \multirow{2}{*}{$\mathrm{c}(\%)$} & \multirow{2}{*}{ DP } & \multirow{2}{*}{$\mathrm{R}^{2}$} & \multicolumn{3}{|c|}{$\mathrm{DE}(\% / \mathrm{h})$} \\
\hline & & & & & & 2,0 & 3,0 & 5,0 \\
\hline 56 & 45,09 & 39,71 & 4,35 & 84,80 & 0,90 & 72,30 & 68,60 & 63,57 \\
\hline 84 & 25,53 & 39,27 & 8,96 & 64,79 & 0,69 & 57,63 & 54,95 & 50,73 \\
\hline 112 & 22,98 & 33,54 & 3,01 & 56,52 & 0,83 & 43,12 & 39,77 & 35,57 \\
\hline \multirow{3}{*}{ Idade corte (dias) } & \multicolumn{8}{|c|}{ FDN } \\
\hline & \multirow{2}{*}{$\mathrm{a}(\%)$} & \multirow{2}{*}{$\mathrm{b}(\%)$} & \multirow{2}{*}{$\mathrm{c}(\%)$} & \multirow{2}{*}{ DP } & \multirow{2}{*}{$\mathrm{R}^{2}$} & \multicolumn{3}{|c|}{$\mathrm{DE}(\% / \mathrm{h})$} \\
\hline & & & & & & 2,0 & 3,0 & 5,0 \\
\hline 56 & 0,03 & 72,15 & 3,89 & 72,18 & 0,96 & 47,67 & 40,76 & 31,59 \\
\hline 84 & 1,79 & 61,44 & 3,15 & 63,23 & 0,95 & 39,36 & 33,25 & 25,52 \\
\hline 112 & 0,13 & 64,20 & 2,03 & 64,33 & 0,95 & 32,50 & 26,07 & 18,70 \\
\hline
\end{tabular}

$\mathrm{a}=$ fração rapidamente degradável; $\mathrm{b}=$ fração lentamente degradável; $\mathrm{c}=$ taxa constante de degradação da fração b; DP= degradabilidade potencial; $\mathrm{DE}=$ degradabilidade efetiva nas taxas de passagem ruminal de 2,$0 ; 3,0$ e $5,0 \% /$ hora.

A produção estacionária de gases do capimelefante verde cortado aos 56 dias se mostrou superior aos demais tratamentos até o tempo de 24

horas de fermentação (Fig. 1), tendo o capimelefante colhido aos 112 dias apresentado, a partir do período de 36 horas, as maiores produções estacionárias.

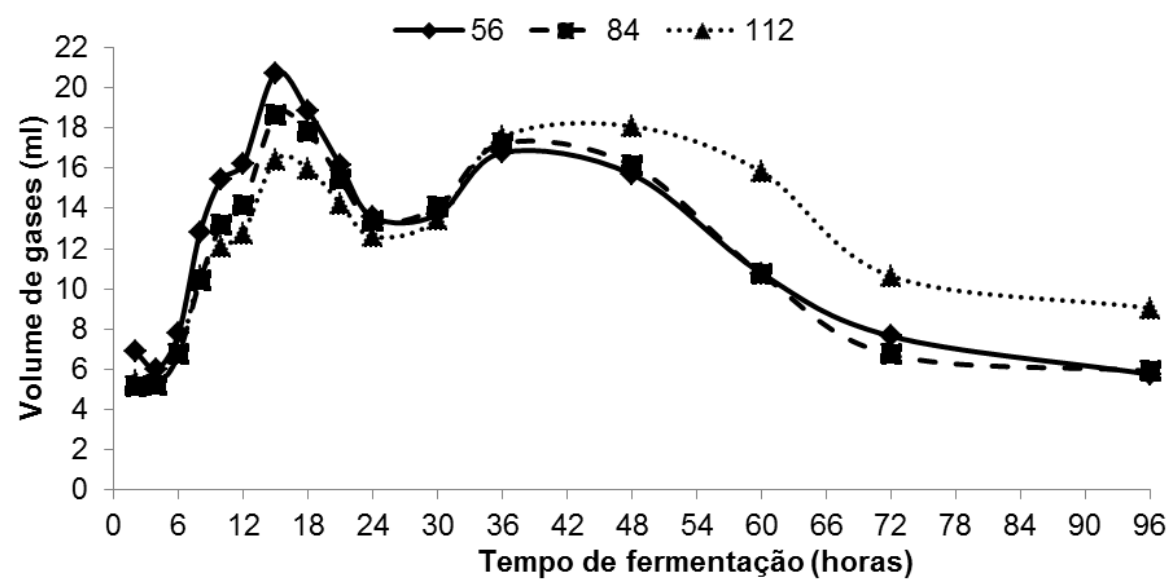

Figura 1. Produção de gases em mL do capim-elefante (Pennisetum purpureum Schum.) verde cortado aos 56, 84 e 112 dias de crescimento.

Enquanto o capim-elefante cortado aos 56 e 84 dias de crescimento apresentou o maior pico de produção de gases após 15 horas de fermentação, o material colhido aos 112 dias atingiu o pico após 48 horas de fermentação, corroborando Velasco
(2011), que encontrou pico de produção de gases após transcorrer o período de 12 a 24 horas de fermentação para o capim Brachiaria decumbens verde cortado aos 56 dias. De forma geral, próximo ao tempo de incubação de 48 horas, 
iniciou-se uma diminuição da produção de gases possivelmente relacionada à redução da disponibilidade de substrato para os microrganismos ruminais.

No tempo de fermentação de seis horas, não houve diferença entre as idades de corte para a produção cumulativa de gases (Tab. 4). Já para os tempos de 12 e 96 horas, as produções de gases do material cortado aos 84 e 112 dias foram semelhantes e inferiores à do capim colhido aos 56 dias. Nos demais tempos de fermentação (24 e 48 horas), as maiores produções foram registradas para o capim-elefante cortado aos 56 dias de crescimento, seguido pela idade de 84 dias e, por último, pela idade de 112 dias.

As produções cumulativas de gases após 96 horas de fermentação foram 210,50mL; 195,34mL e $194,10 \mathrm{~mL}$ para o capim-elefante colhido aos 56 , 84 e 112 dias de idade, respectivamente, refletindo os maiores teores de compostos fenólicos (lignina) (Tab. 1) que se ligam aos componentes da parede celular e, assim, afetando a extensão da degradação da forrageira (Jung, 1989; Jung e Allen, 1995).

Tabela 4. Produção cumulativa de gases (PAG) em mL/g de matéria seca (MS) após seis, 12, 24, 48 e 96 horas de fermentação para o capim-elefante (Pennisetum purpureum Schum.) verde cortado aos 56,84 e 112 dias de crescimento

\begin{tabular}{lccccc}
\hline \multirow{2}{*}{ Idade corte (dias) } & \multicolumn{5}{c}{ Períodos de fermentação (horas) } \\
\cline { 2 - 6 } & 6 & 12 & 24 & 48 & 96 \\
\hline 56 & $21,99 \mathrm{a}$ & $68,69 \mathrm{a}$ & $148,55 \mathrm{a}$ & $196,85 \mathrm{a}$ & $210,50 \mathrm{a}$ \\
84 & $17,76 \mathrm{a}$ & $58,83 \mathrm{~b}$ & $130,14 \mathrm{~b}$ & $178,15 \mathrm{~b}$ & $195,34 \mathrm{~b}$ \\
112 & $21,22 \mathrm{a}$ & $60,56 \mathrm{~b}$ & $118,73 \mathrm{c}$ & $171,50 \mathrm{c}$ & $194,10 \mathrm{~b}$ \\
\hline
\end{tabular}

Médias seguidas de letras distintas na coluna diferem entre si pelo teste $\mathrm{SNK}(\mathrm{P}<0,05)$.

Observou-se que, para o período de fermentação de seis horas (Tab. 5), o valor da degradabilidade da matéria seca (DMS) do capim-elefante verde colhido aos 56 dias de crescimento foi superior ao obtido para a capim com 84 dias, sendo a forragem com 112 dias intermediária.

Tabela 5. Degradabilidade da matéria seca e da matéria orgânica em porcentagem (\%), após seis, 12, 24, 48 e 96 horas de fermentação para o capim-elefante (Pennisetum purpureum Schum.) verde cortado aos 56, 84 e 112 dias de crescimento

\begin{tabular}{cccccc}
\hline & \multicolumn{5}{c}{ Período de fermentação (horas) } \\
\cline { 2 - 5 } Idade corte (dias) & 6 & 12 & 24 & 48 & 96 \\
\cline { 2 - 5 } & $11,17 \mathrm{a}$ & $27,11 \mathrm{a}$ & $41,55 \mathrm{a}$ & $57,22 \mathrm{a}$ & $63,8 \mathrm{a}$ \\
\hline 56 & $3,64 \mathrm{~b}$ & $17,99 \mathrm{~b}$ & $35,52 \mathrm{~b}$ & $47,05 \mathrm{~b}$ & $51,76 \mathrm{~b}$ \\
84 & $6,41 \mathrm{ab}$ & $15,06 \mathrm{~b}$ & $35,33 \mathrm{~b}$ & $42,95 \mathrm{~b}$ & $48,26 \mathrm{~b}$ \\
\hline 112 & & \multicolumn{5}{c}{ Matéria orgânica } \\
\hline 56 & $12,83 \mathrm{a}$ & $29,88 \mathrm{a}$ & $47,50 \mathrm{a}$ & $57,01 \mathrm{a}$ & $65,62 \mathrm{a}$ \\
& $6,89 \mathrm{a}$ & $20,74 \mathrm{~b}$ & $37,67 \mathrm{~b}$ & $49,35 \mathrm{~b}$ & $54,11 \mathrm{~b}$ \\
112 & $9,30 \mathrm{a}$ & $17,72 \mathrm{~b}$ & $36,13 \mathrm{~b}$ & $45,99 \mathrm{~b}$ & $49,94 \mathrm{~b}$ \\
\hline
\end{tabular}

Médias seguidas de letras distintas na coluna diferem entre si pelo teste SNK $(\mathrm{P}<0,05)$.

Em relação à degradabilidade de matéria orgânica (DMO), não houve diferenças entre os tratamentos para o tempo de seis horas. Em contrapartida, os valores referentes à DMS e à DMO do capim cortado aos 56 dias foram superiores em relação aos demais cortes que não variaram entre si, para os tempos de 12 a 96 horas de fermentação.

A partir de 12 horas de fermentação, Velasco (2011) também obteve valores de degradabilidade da MS superiores para o capim B. decumbens cortado aos 56 dias, quando comparado a 84 e 112 
dias de rebrota. Os maiores valores de degradabilidade obtidos para o capim colhido aos 56 dias de crescimento corroboram as maiores produções cumulativas de gases (Tab. 4), uma vez que esses gases são oriundos do processo fermentativo e/ou da neutralização dos ácidos graxos voláteis pela solução tampão. Assim como no presente estudo, outros trabalhos relataram queda da DMS em razão do estádio de maturação do capim (Velasco, 2011; Carvalho, 2012).

\section{CONCLUSÕES}

O corte da planta inteira de capim-elefante para utilização como forragem verde deve ser realizado aos 56 dias de rebrota, a fim de se obter um material com elevado potencial de degradação e maior valor nutricional.

\section{REFERÊNCIAS}

CARVALHO, W.T.V. Valor nutricional do feno de Tifton 85 em quatro idades. 2012. 196f. Tese (Doutorado em Zootecnia) - Universidade Federal de Minas Gerais, Belo Horizonte, MG.

EUCLYDES, R.F. Manual de utilização do programa SAEG (sistema para análises estatísticas e genéticas). Viçosa, MG: Universidade Federal de Viçosa, 1983.

FRANCE, J.; DHANOA, M.S.; THEODOROU, M.K. et al. A model to interpret gas accumulation profiles associated with in vitro degradation of ruminant feeds. J. Theoret. Biol., v.163, p.99-111, 1993.

INTERNATIONAL official methods of analysis, 16 ed. Washington, D.C.: AOAC, 1995.

JUNG H.G.; ALLEN M.S. Characteristics of plant cell walls affecting intake and digestibility of forages by ruminants. J. Anim. Sci., v.73, p.2774-2790, 1995 .

JUNG, H.G. Forage lignins and their effect on fiber digestibility. Agron. J., v.81, p.33-38, 1989.

LIMA, E.S.; SILVA, J.F.C.; VASQUEZ, H.M. et al. Composição e digestibilidade in vitro de genótipos de capim-elefante, aos 56 dias de rebrota. Arch. Zootec., v.57, p.282, 2008.
MACHADO, P.A.S.; VALADARES FILHO, S.C.; VALADARES, R.F.D. et al. Avaliação nutricional do capim-elefante (Cameroon) em diferentes idades de rebrotação. Rev. Bras. Zootec., v.37, p.1121-1128, 2008.

MAURICIO, R.M.; MOULD, F.L.; DHANOA, M.S. et al. A semi-automated in vitro gas production technique for ruminants feedstuff evaluation. Anim. Feed Sci. Technol., v.79, p.321330, 1999.

MAURICIO, R.M.; PEREIRA, L.G.R.; GONÇALVES, L.C. et al. Relação entre pressão e volume para implantação da técnica in vitro semi-automática de produção de gases na avaliação de forrageiras tropicais. Arq. Bras. Med. Vet. Zootec., v.55, p.216-219, 2003.

McDONALD, J. A revised model for the estimation of protein degradability in the rumen. J. Agric. Sci., v.96, p.251-252. 1981.

OFFICIAL methods of analysis. 13.ed. Washington, D.C.: AOAC, 1980. 1015p.

ORSKOV, E.R.; McDONALD, J. The estimation of protein degradability in the rumen from incubation measurements of feed in weighted according to rate of passage. J. Agric. Sci., v.92, p.499-503, 1979.

SANTOS, F.A.P. Metabolismo de proteínas. In: BERCHIELLI, T.T.; PIRES, A.V.; OLIVEIRA, S.G. Nutrição de ruminantes. Jaboticabal: FUNEP, 2006. p.255-284.

SAS/STAT Software: syntax. Version 6.12. Cary, NC: SAS Institute Inc., 1993. 151p.

SILVA, J.F.; LEÃO, M.I. Fundamentos de nutrição dos ruminantes. Piracicaba: Ceres, 1978. $379 \mathrm{p}$.

SILVA, P.A.; VALADARES FILHO, S.C.; VALADARES, R.F.D. et al. Valor energético do capim-elefante em diferentes idades de rebrota e estimativa da digestibilidade in vivo da fibra em detergente neutro. Arq. Bras. Med. Vet. Zootec., v.59, p.711-718, 2007.

THE NUTRIENT requirements of ruminant livestock. Supply 1. Slough: Commonwealth Agricultural Bureaux / ARC, 1984. 45p. 
THEODOROU, M.K.; WILLIAMS, B.A.; DHANOA, M.S. et al. A simple gas production method using a pressure transducer to determine the fermentation kinetics of ruminal feeds. Anim. Feed Sci. Technol., v.48, p.185-197, 1994.

TOMICH, T.R.; GONÇALVES, L.C.; PEREIRA, L.G.R.; MAURÍCIO, R.M.; TOMICH, R.G.P. et al. Degradabilidade ruminal da matéria seca, da proteína bruta e da fração fibrosa de forrageiras manejadas em regime de corte. In: REUNIÃO ANUAL DA SOCIEDADE BRASILEIRA DE ZOOTECNIA, 40., 2003, Santa Maria. Anais... Santa Maria: [s.n.] 2003. p.1.

VALADARES FILHO, S.C. Utilização da técnica in situ para avaliação dos alimentos. In: SIMPÓSIO INTERNACIONAL DE PRODUÇÃO DE RUMINANTES, 1994, Maringá. Anais... Maringá: EDUEM, 1994. p.95-118.
VAN SOEST, P.J. Nutritional ecology of the ruminant. 2.ed. Ithaca, New York: Cornell University Press, 1994. 476p.

VAN SOEST, P.J.; ROBERTSON, J.B.; LEWIS, B.A. Official for dietary fiber, neutral detergent fiber and non-starch polysaccharides in relation to animal nutrition. J. Dairy Sci., v.74, p.3583-3597, 1991.

VELASCO, F.O. Valor nutritivo da Brachiaria decumbens em três idades. 2011. 98f. Tese (Doutorado em Zootecnia) - Universidade Federal de Minas Gerais, Belo Horizonte, MG. 